\title{
Stress Spillover of Health Symptoms From Healthy Spouses to Patient Spouses in Older Married Couples Managing Both Diabetes and Osteoarthritis
}

\author{
Jeremy B. Yorgason \\ Brigham Young University - Provo \\ Susanne O. Roper \\ Brigham Young University - Provo \\ Jonathan G. Sandberg \\ Brigham Young University - Provo, jonathan_sandberg@byu.edu \\ Cynthia A. Berg \\ University of Utah \\ Follow this and additional works at: https://scholarsarchive.byu.edu/facpub \\ Part of the Other Social and Behavioral Sciences Commons
}

\section{Original Publication Citation}

Yorgason, J. B., Roper, S. O., Sandberg, J. G., \& Berg, C. A. (2012). Stress spillover of health symptoms from healthy spouses to patient spouses in older married couples managing both diabetes and osteoarthritis. Families, Systems, \& Health, 30(4), 330.

\section{BYU ScholarsArchive Citation}

Yorgason, Jeremy B.; Roper, Susanne O.; Sandberg, Jonathan G.; and Berg, Cynthia A., "Stress Spillover of Health Symptoms From Healthy Spouses to Patient Spouses in Older Married Couples Managing Both Diabetes and Osteoarthritis" (2012). Faculty Publications. 4076.

https://scholarsarchive.byu.edu/facpub/4076

This Peer-Reviewed Article is brought to you for free and open access by BYU ScholarsArchive. It has been accepted for inclusion in Faculty Publications by an authorized administrator of BYU ScholarsArchive. For more information, please contact ellen_amatangelo@byu.edu. 


\title{
Stress Spillover of Health Symptoms From Healthy Spouses to Patient Spouses in Older Married Couples Managing Both Diabetes and Osteoarthritis
}

\author{
Jeremy B. Yorgason, $\mathrm{PhD}$, \\ Susanne O. Roper, PhD, \\ and Jonathan G. Sandberg, PhD \\ Brigham Young University
}

\author{
Cynthia A. Berg, PhD \\ University of Utah
}

\begin{abstract}
Many studies examining illness within marriage have investigated how illness in one spouse influences the other spouse. In later-life marriages, where both spouses are more likely to have health challenges, there is an increased likelihood that health symptoms from both spouses affect each other. In the current study we examined how health symptoms in a "healthy" spouse may exacerbate health problems in a partner (the patient) who is managing multiple chronic illnesses. Surveys were collected across 14 days from 27 later-life couples where patients had both diabetes and osteoarthritis. Results indicated that higher healthy spouse symptoms were generally associated with higher patient symptoms, suggesting a spillover effect. Spouse reports of positive and negative mood were inversely linked with patient health outcomes. Spouse reports of higher positive marital interactions were surprisingly linked with higher patients' arthritis activity and activity limitations, possibly indicating a compensatory effect where marital interactions increase with symptoms. Daily spouse reports of positive marital interactions and mood were linked with patient health outcomes even after the spillover of health symptoms was taken into account.
\end{abstract}

Keywords: health, coping with illness/disability, marriage, comorbid illnesses

A number of studies examining illness in marriage have indicated that the health of a partner experiencing illness (the "patient") can affect both the physical and mental health of their spouse (Bigatti \& Cronan, 2002; Pruchno, Wilson-Gendersen, \& Cartwright, 2009; Westman, Keinan, Roziner, \& Benyamini, 2008; Yorgason, Almeida, Neupert, Spiro, \& Hoff-

This article was published Online First November 12, 2012. Jeremy B. Yorgason, $\mathrm{PhD}$, Susanne O. Roper, $\mathrm{PhD}$, and Jonathan G. Sandberg, PhD, School of Family Life, Brigham Young University; Cynthia A. Berg, PhD, Department of Psychology, University of Utah.

Funding for this study was provided by the Marjorie Pay Hinckley Chair, the Family Studies Center, and the Gerontology Center at Brigham Young University. We express appreciation to the couples who participated in this study, and to the students who assisted with data collection.

Correspondence concerning this article should be addressed to Jeremy B. Yorgason, PhD, School of Family Life, Brigham Young University, 2079 JFSB, Provo, UT 84602. E-mail: Jeremy_yorgason@byu.edu man, 2006). These studies address the important role that illness can play in marriage, yet have neglected to consider ways that healthy spouses' own illness experiences may exacerbate or lessen patients' chronic illness symptoms. In later adulthood, when both spouses often contend with health concerns (Bookwala \& Schulz, 1996) and possibly multiple chronic illnesses simultaneously (Pastor, Makuc, Reuben, \& Xia, 2002), stress from illness symptoms may be reciprocal. That is, strain from health problems may originate in the patient and affect their healthier partner, or they may originate in the healthier partner and affect the patient spouse.

\section{Stress Spillover: A Guiding Framework}

Health symptoms experienced by one marital partner likely influence the well-being of the other spouse through what has been called a "spillover" effect. For patients living with chronic health problems, stress from daily 
health symptoms may spill over and negatively affect their spouse (Berg \& Upchurch, 2007; Westman, 2001). Studies of general health (Westman et al., 2008) and daily health symptoms (Bigatti \& Cronin, 2002) both provide evidence of spillover effects of health declines within marriage. Westman and Vinokur (1998) suggest that the experiences of one spouse, such as health symptoms, may influence the other spouse through couple interactions. The current literature does not provide a clear sense of how factors such as marital interactions or mood are linked to partner outcomes even in the presence of health symptoms.

Regarding marital interactions, a healthier spouse's symptoms (e.g., headache or joint pain) may lead to negative marital interactions that thereby affect the health symptoms of the patient. However, older adults may manage such health symptoms effectively, especially in the context of late-life marriages, which are frequently characterized by high marital satisfaction (Henry, Berg, Smith, \& Florsheim, 2007) and greater positive sentiment override (Story et al., 2007).

Research also has linked physical health symptoms in one spouse with mood or mental distress in the other. For example, poor health in patients with osteoarthritis has been associated with partners' mental distress levels (Stephens, Martire, Creamans-Smith, Druley, \& Wojno, 2006); having fibromyalgia has been linked with poorer partner physical and mental health (Bigatti \& Cronan, 2002); lower self-rated health has been related to poorer marital quality for partners (Booth \& Johnson, 1994; Yorgason, Booth, \& Johnson, 2008); and higher daily health symptoms among husbands has been associated with higher levels of wife negative mood (Yorgason et al., 2006). Addressing marital interactions, mood, and health symptoms simultaneously would help to consider their individual effects while acknowledging their competing influences.

Although considerable research has examined the effects of illness spillover within marriage, there is a surprising gap regarding how the daily health experience of a healthy partner can impact the health of the patient. This nonsystemic approach ignores existing theory and research regarding the dyadic nature of illness for later life couples (Berg \& Upchurch, 2007). In addition, research findings in literature re- lated to both caregiving and Type 1 diabetes suggests that the experience of a non-ill loved one clearly has an impact on both the quality of life and functionality of the patient (Burgener \& Twigg, 2002; Whittemore, Urban, Tamborlane, \& Grey, 2003).

\section{The Current Study}

The focus of this study is to identify how a spouse's illness symptoms relate to patient diabetes and arthritis symptoms, while taking into account the spouse's reports of daily marital interactions and mood. Diabetes and arthritis were the focus of the current study as they represent illnesses that increase in incidence and severity with age and can impact daily quality of life (e.g., regular monitoring of blood glucose and medication administration, daily pain and mobility constraints). Type 2 diabetes is a major public health concern, affecting nearly $20 \%$ of middle-aged and older Americans (Wray, Alwin, McCammon, Manning, \& Best, 2006), and is among the top 10 leading causes of death in America (Xu, Kochanek, Murphy, Tejada-Vera, 2010). Arthritis also has become a major chronic illness concern for older adults, with prevalence rates among that age group around 50\% (Administration on Aging, 2009; Lawrence et al., 1998). Thus, a daily, couple-based perspective is needed to gain a better understanding of the experience of comanaging multiple chronic illnesses in later life (Berg \& Upchurch, 2007).

The presence of multiple chronic illnesses can contribute to increased psychological stress, decreased life satisfaction, and lower levels of well-being (Piazza, Charles, \& Almeida, 2007). Patients with multiple chronic health conditions also report more daily stressors (Piazza et al., 2007) and accomplishing less than they would like (Center on an Aging Society, 2003). Furthermore, the presence of one illness may require medications and/or lifestyle changes that are incompatible with other chronic illnesses (Bayliss, Steiner, Fernald, Crane, \& Main, 2003; Yorgason et al., 2010).

For older couples, both spouses may experience multiple chronic illnesses and repercussions of multiple illnesses might interact or be additive. Furthermore, marital partners may be especially attuned to one another's health chal- 
lenges due to the salience of the marital relationship in later life (Henry et al., 2007).

In this study a daily diary research design was used to examine covariation of daily husband and wife health symptoms. This method involves the daily measurement of the main study variables, which may be assessed through observation, self-report, or qualitative narrative (see Gunthert \& Wenze, 2012). Self-report daily diary surveys allow for the exploration of microprocesses and the lived experiences of couples related to health (Larson \& Almeida, 1999; Laurenceau \& Bolger, 2005; Bolger, Davis, \& Rafaeli, 2003). Although recent research has examined daily health experiences of persons with chronic conditions (Piazza et al., 2007), as well as daily marital support in the context of diabetes in later life (Iida, Stephens, Rook, Franks, $\&$ Salem, 2010), few studies have examined how husband and wife health covary on a daily basis. Furthermore, when daily health symptoms of one spouse are linked with the daily health of the other, it is unclear whether this association is a function of the health symptoms or whether marital interactions or emotional transmission account for the connections. The purpose of this study is to examine the association of physical health symptoms in a more healthy spouse with chronic illness symptoms in a patient managing two illnesses common in later life: diabetes and osteoarthritis. A secondary purpose is to identify if spouse mood and marital interactions are important predictors of patient symptoms, above and beyond the presence of their own health symptoms.

\section{Hypotheses}

1. Higher than average and higher daily physical symptoms of a spouse will be related to daily diabetes concerns, arthritis symptoms, and health limitations of the patient.

2. In addition to daily physical symptoms, daily positive and negative marital interactions and daily positive and negative mood of a spouse will be linked to daily diabetes concerns, arthritis symptoms, and health limitations of the patient.
We expect that positive marital interaction and mood will be linked with fewer health problems, and that negative marital interaction and mood will be linked with more patient health problems. Although we expect all predictors to be linked to patient health, our examination of the relative consistency and strength of these associations is exploratory.

\section{Method}

\section{Sample}

Participants were 28 married couples from a metropolitan county in a western state. Patients were recruited through a diabetes management clinic and education classes at two hospitals. The two hospitals (two of five in the county) served patients of varying socioeconomic levels and are among the largest hospitals in the area. Couples were recruited if (a) the patient was diagnosed with both diabetes and osteoarthritis, (b) one spouse was over the age of 59 and was married, and (c) both spouses were willing to participate. Patients identified through hospital medical records to fit our criteria were invited to participate, and eight of 19 eligible patients agreed to participate. Reasons for nonparticipation included not having enough time, believing the research was too personal, or lack of interest. Twenty additional couples were recruited from diabetes support groups and education classes provided to patients by the same diabetes management clinics. One spouse who agreed to participate in the study only completed the baseline and qualitative interview, but did not complete the daily diary portion of the study. Data from that couple was dropped from the current analysis, resulting in data from 27 couples in the present analysis. Approximately 20\% of eligible couples at the diabetes classes/groups declined participation. Both the affiliated hospital and university Institutional Review Boards approved the study.

Most couples were Caucasian (89\%) and had been married on average 41.69 years $(S D=$ 13.55; see Table 1 for demographic description). The mean age of the patient was 67.70 years $(S D=7.41)$; the average age of their spouse was 67.67 years $(S D=7.94)$. Fourteen of the patients $(52 \%)$ were female. Five patients (19\%) and seven spouses (24\%) were currently employed. For the patients, the average time 
Table 1

Demographic Information for Patients and Spouses in the Sample

\begin{tabular}{lcc}
\hline \multicolumn{1}{c}{ Variable } & Patient & Spouse \\
\hline$\%$ Female & $52 \%$ & $48 \%$ \\
$\%$ Employed & $19 \%$ & $24 \%$ \\
$M$ Age years $(S D)$ & $67.70(7.41)$ & $67.67(7.94)$ \\
$\%$ with diabetes & $100 \%$ & $37.00 \%$ \\
Years since diagnosis $(S D)$ & $10.24(9.99)$ & - \\
Severity $(S D)$ & $2.59(.80)$ & $1.44(.53)$ \\
$\%$ with arthritis & $100 \%$ & $59.30 \%$ \\
Years since diagnosis $(S D)$ & $15.95(13.16)$ & - \\
Severity $(S D)$ & $2.58(.81)$ & $1.82(.81)$ \\
Number of chronic illnesses & & \\
$(S D)$ & $4.96(2.08)$ & $3.33(2.11)$ \\
\hline
\end{tabular}

Note. Severity $1=$ not bad at all; $2=\operatorname{not}$ too bad; $3=$ bad.

since their diagnosis with diabetes was 10.24 years $(S D=9.99)$ and 15.95 years $(S D=$ 13.16) since their diagnosis with osteoarthritis. Patients and their spouses also reported an average of $4.96(S D=2.08)$ and $3.33(S D=2.11)$ chronic illnesses, respectively, $t=2.85, d f=$ $52, p=.006$.

Eight couples reported both spouses being diagnosed with both illnesses. In these cases, the spouse with more severe symptoms was designated as the patient. Preliminary analyses showed that couples where both spouses had arthritis and diabetes had slightly higher levels of daily negative mood $(t=-3.41, d f=696$, $p=.001)$ than the remainder of the sample. We found no significant differences in positive mood, activity limitations, or age. Because differences were viewed as minor, we included all couples in the final models.

\section{Procedures}

Trained researchers visited couples in their homes, obtained informed consent, and left a baseline questionnaire for them to complete independently. After approximately 1 week, researchers conducted a semistructured qualitative interview with each couple. The interview consisted of three major sections which explored the story of the patient's health problems, the couples' belief systems and meanings, and the couples' resilience to their health challenges (see Yorgason et al., 2010 for a complete description of methodology and data analysis). Daily diary survey procedures were explained at the time of the interview. Both the patients and their spouses were asked to independently complete daily diary surveys in the evening for 14 consecutive days. Couples received a reminder telephone call each evening and a \$50 gift card after participating.

\section{Measures}

Patients assessed their daily arthritis symptoms with one item evaluating how active their arthritis was $(1=$ Not active at all; $4=$ Very active). Average scores were $2.52(S D=.86)$ for wives and $2.38(S D=.85)$ for husbands.

Patients completed one question that asked if their blood sugar levels caused them concern that day $(1=$ No concern at all; $4=$ Quite a bit of concern). Mean scores were 1.71 (SD = $1.01)$ for wives and $1.64(S D=.71)$ for husbands.

Activity limitations were measured in patients using four items from the SF36 health survey, as well as one item related to medicine side effects. Items assessed if patients accomplished less than they would like to, spent less time working, felt limitations in what they could do, and had difficulty performing tasks on a given day (Hays, Sherbourne, \& Mazel, 1993). The medication side effect item asked if patients experienced side effects from medicines they were taking that required them to change their activities. Responses included (1) No, (2) Yes, Slightly, (3) Yes, Very Much; scores were aggregated with higher scores indicating higher activity limitations. We calculated a reliability coefficient (.86) within a three-level model (items nested within days nested within person; Shavelson \& Webb, 1991). Average scores were $8.46(S D=2.49)$ for wives and 6.79 $(S D=2.11)$ for husbands.

A shortened version of the physical symptom checklist (Larsen \& Kasimatis, 1991) was used to assess spouse health symptoms on each day of the study. Thirteen items measured symptoms including aches/pain (headaches, backaches, and muscle soreness), gastrointestinal symptoms (poor appetite, nausea/upset stomach, constipation/diarrhea), chest pain or dizziness (symptoms often associated with cardiovascular functioning), and upper respiratory infection symptoms (sore throat, runny nose, congestion). Two additional items (cold/flu symptoms and joint pain) were also included. 
Items were summed creating a count variable, with higher scores reflecting more symptoms for each day. Average scores were $1.84(S D=$ $1.15)$ for husband spouses and $2.22(S D=1.96)$ for wife spouses.

Spouses of the patients with diabetes and arthritis identified whether 12 events involving a spouse had occurred in the last 24 hours (adapted from Neff \& Karney, 2005). For each event, spouses indicated whether or not that event had happened to them that day $(1=$ Yes and $0=\mathrm{No}$ ). Items included both positive and negative interactions. Positive interactions were measured with eight items including whether or not a spouse said something that made respondents feel loved, if they enjoyed a joint leisure activity together, if the spouse showed interest in events of the respondent's day, if the spouse listened to or comforted the respondent, if the respondent cared for or looked after their spouse, if the respondent shared physical intimacy with their spouse, if the respondent was helped by their spouse with something important, and if the respondent listened to or comforted their spouse. Four negative items included if the couple had an argument, if they were unable to spend time together that day, if the spouse let the respondent down or broke a promise, or if the respondent was criticized by the spouse. Positive events were summed to create a positive interaction variable, and negative events were summed to create a negative interaction variable. The average of positive and negative marital interactions by wife spouses was $4.17(S D=2.18)$ and $.22(S D=.56)$ respectively. The average of positive and negative marital interactions by husband spouses was $3.72(S D=2.26)$ and $.20(S D=.46)$ respectively. A measure of global marital happiness was correlated mostly in expected directions with the daily marital interaction variables (wife global marital happiness correlated with wife positive marital interactions $r=.18, p<$ .001 and with wife negative marital interactions $r=-.24 p<.001$; husband global marital happiness was not correlated with husband positive marital interactions $r=.02, p>.05$ but was with husband negative marital interactions $r=-.32 p<.001$ ).

Patient spouses completed 10 positive items and 10 negative items from the Positive and Negative Affect Schedule (PANAS; Watson, Clark, \& Tellegen, 1988). The PANAS assessed the extent to which the respondents experienced feelings and emotions (e.g., upset, enthusiastic) on a given day, with response options anchored by (1) Very slightly or not at all and (5) Extremely. The PANAS has typically had high internal consistency reliabilities (e.g., .84 to .90 ; Watson et al., 1988). Scale reliabilities calculated within a multilevel analysis using the current data indicated coefficients of .91 for positive and .86 for negative daily mood. The average scores for positive and negative mood were $31.68(S D=9.96)$ and $13.17(S D=5.61)$ respectively for husband spouses, and 30.81 $(S D=10.04)$ and $13.25(S D=5.87)$ respectively for wife spouses.

\section{Data Analysis}

Multilevel models were estimated using SAS Proc Mixed to predict daily diabetes concerns, arthritis symptoms, and health limitations in either the husband or the wife that was the patient. Spouse predictors included daily health symptoms, daily positive and negative marital interactions, and daily positive and negative mood. After entering daily physical health symptoms (Model 2, Tables 2, 3 and 4), marital interactions and mood predictors were examined in separate models to avoid problems of collinearity (Models 3-6, Tables 2-4). Last, as an exploratory analysis, all predictors were included in a final model (Model 7, Tables 2-4). Two separate variables are indicated for each predictor in the study with the first representing each person's daily deviation from their average (person mean centered-within person predictor, Level 1 of the model), and the second representing the average score for each person across the 14 days, centered around the sample average (group mean centered-between person predictor, Level 2 of the model). Gender of the patient is entered in the model as a Level 2 predictor. Also, interaction terms involving gender with each predictor were estimated. Models were estimated using a Toeplitz error structure, as this allowed residuals on days that were closer to each other to be more highly correlated.

\section{Results}

Three initial models (Model 1, Tables 2, 3, and 4) were estimated to explore intraclass correlation coefficients (ICCs) for each of the patient health outcomes and to examine the 
Table 2

Unstandardized Estimates for Spouse Daily Physical Symptoms, Daily Positive and Negative Interactions, Daily Positive and Negative Mood, Predicting Patient Blood Sugar Level Concerns ( $\mathrm{N}=27$ Couples)

\begin{tabular}{|c|c|c|c|c|c|c|c|}
\hline & \multicolumn{7}{|c|}{ Patient blood sugar level concerns } \\
\hline & Model 1 & Model 2 & Model 3 & Model 4 & Model 5 & Model 6 & Model 7 \\
\hline & Empty & $\begin{array}{l}\text { Physical } \\
\text { symptoms }\end{array}$ & $\begin{array}{l}\text { Positive } \\
\text { interactions }\end{array}$ & $\begin{array}{l}\text { Negative } \\
\text { interactions }\end{array}$ & $\begin{array}{l}\text { Positive } \\
\text { mood }\end{array}$ & $\begin{array}{l}\text { Negative } \\
\text { mood }\end{array}$ & $\begin{array}{c}\text { All } \\
\text { predictors }\end{array}$ \\
\hline Intercept & 1.62 & 1.49 & 1.52 & 1.53 & 1.45 & 1.58 & 1.62 \\
\hline $\begin{array}{l}\text { Spouse average physical } \\
\text { symptoms (PS) }\end{array}$ & & $.27^{* *}$ & $.21^{*}$ & $.32^{* *}$ & $.27^{* *}$ & .18 & .14 \\
\hline $\begin{array}{l}\text { Spouse deviation from daily } \\
\text { average PS }\end{array}$ & & -.03 & -.03 & -.03 & -.04 & -.05 & -.05 \\
\hline $\begin{array}{l}\text { Spouse average positive } \\
\text { interactions (PI) }\end{array}$ & & & .10 & & & & .09 \\
\hline $\begin{array}{l}\text { Spouse deviation from daily } \\
\text { average PI }\end{array}$ & & & -.01 & & & & .00 \\
\hline $\begin{array}{l}\text { Spouse average negative } \\
\text { interactions (NI) }\end{array}$ & & & & -.29 & & & -.37 \\
\hline $\begin{array}{l}\text { Spouse deviation from daily } \\
\text { average NI }\end{array}$ & & & & .03 & & & -.04 \\
\hline $\begin{array}{l}\text { Spouse average positive } \\
\text { mood }(\mathrm{PM})\end{array}$ & & & & & -.01 & & -.02 \\
\hline $\begin{array}{l}\text { Spouse deviation from daily } \\
\text { average PM }\end{array}$ & & & & & -.00 & & -.00 \\
\hline $\begin{array}{l}\text { Spouse average negative } \\
\text { mood (NM) }\end{array}$ & & & & & & .04 & .06 \\
\hline $\begin{array}{l}\text { Spouse deviation from daily } \\
\text { average NM }\end{array}$ & & & & & & $.01^{\dagger}$ & .01 \\
\hline $\begin{array}{l}\text { Patient gender }(1=\text { female } \\
0=\text { male })\end{array}$ & .14 & -.10 & -.05 & -.11 & -.04 & -.11 & .07 \\
\hline \# of parameters/ $N$ of days & $19 / 365$ & $21 / 343$ & $23 / 342$ & $23 / 343$ & $23 / 314$ & $23 / 316$ & 29/309 \\
\hline-2 Log likelihood/AIC & $672 / 700$ & $645 / 673$ & $651 / 679$ & $648 / 676$ & $617 / 645$ & $619 / 647$ & $627 / 655$ \\
\hline $\begin{array}{l}\text { Within-person variance/ } \\
\text { between-person variance }\end{array}$ & $.50 / .34$ & $.55 / .14$ & $.52 / .15$ & $.54 / .16$ & $.49 / .21$ & $.62 / .09$ & $.50 / .17$ \\
\hline
\end{tabular}

Note. "Average" physical symptoms, positive interactions, negative interactions and mood indicate Level 2 effects; "Deviation from daily average" indicates Level 1 effects. Controls in all models include years married, husband level of education, and years since diabetes diagnosis.

${ }^{\dagger} p \leq .10 .{ }^{*} p \leq .05$. ${ }^{* * *} p \leq .01 .{ }^{* * *} p \leq .001$.

amount of within- versus between-person variability. The ICCs for patient outcomes included concern with diabetes (.41), arthritis activity (.32), and activity limitations (.26), indicating somewhat less between-person variability than within-person variability for these constructs. Still, these ICC values indicate variability that could be accounted for by both Level 1 and Level 2 predictors.

Findings support our first hypothesis of health symptom spillover (Model 2, Tables 2, 3, and 4). Specifically, higher than average (Level 2) physical symptoms in spouses were linked to higher levels of blood sugar level concerns, arthritis activity, and activity limitations in the patients. Also, higher than daily average (Level
1) physical symptoms in spouses were related to higher levels of arthritis activity and activity limitations in the patients.

Some evidence was found supporting our second hypothesis of spouse reports of marital interactions and mood being associated with patient's health above and beyond the spillover of physical symptoms. First, spouse reports of higher than average (Level 2) positive marital interactions were related to higher patient arthritis activity (Model 3, Table 3). That higher positive marital interactions were linked with higher arthritis activity was contrary to what was expected. Second, (Models 5 and 6, Tables 3 and 4), higher than daily average (Level 1) positive mood was 
Table 3

Unstandardized Estimates for Spouse Daily Physical Symptoms, Daily Positive and Negative Interactions, Daily Positive and Negative Mood, Predicting Patient Arthritis Activity ( $\mathrm{N}=27$ Couples)

\begin{tabular}{|c|c|c|c|c|c|c|c|}
\hline & \multicolumn{7}{|c|}{ Patient arthritis activity } \\
\hline & Model 1 & Model 2 & Model 3 & Model 4 & Model 5 & Model 6 & Model 7 \\
\hline & Empty & $\begin{array}{l}\text { Physical } \\
\text { symptoms }\end{array}$ & $\begin{array}{l}\text { Positive } \\
\text { interactions }\end{array}$ & $\begin{array}{l}\text { Negative } \\
\text { interactions }\end{array}$ & $\begin{array}{l}\text { Positive } \\
\text { mood }\end{array}$ & $\begin{array}{l}\text { Negative } \\
\text { mood }\end{array}$ & $\begin{array}{c}\text { All } \\
\text { predictors }\end{array}$ \\
\hline Intercept & 2.38 & 2.33 & 2.41 & 2.36 & 2.32 & 2.31 & 2.29 \\
\hline $\begin{array}{l}\text { Spouse average physical } \\
\text { symptoms (PS) }\end{array}$ & & $.15^{*}$ & .06 & $.17^{\dagger}$ & $.14^{\dagger}$ & .17 & -.07 \\
\hline $\begin{array}{l}\text { Spouse deviation from daily } \\
\text { average PS }\end{array}$ & & $.10^{* * *}$ & $.10^{* *}$ & $.10^{* *}$ & $.08^{*}$ & $.10^{* *}$ & $.07^{*}$ \\
\hline $\begin{array}{l}\text { Spouse average positive } \\
\text { interactions (PI) }\end{array}$ & & & $.16^{* *}$ & & & & $.23^{* *}$ \\
\hline $\begin{array}{l}\text { Spouse deviation from daily } \\
\text { average PI }\end{array}$ & & & -.03 & & & & -.01 \\
\hline $\begin{array}{l}\text { Spouse average negative } \\
\text { interactions (NI) }\end{array}$ & & & & -.13 & & & .49 \\
\hline $\begin{array}{l}\text { Spouse deviation from daily } \\
\text { average NI }\end{array}$ & & & & .03 & & & -.04 \\
\hline $\begin{array}{l}\text { Spouse average positive } \\
\text { mood }(\mathrm{PM})\end{array}$ & & & & & -.01 & & -.01 \\
\hline $\begin{array}{l}\text { Spouse deviation from daily } \\
\text { average PM }\end{array}$ & & & & & $-.02^{* * * *}$ & & $-.02^{* * *}$ \\
\hline $\begin{array}{l}\text { Spouse average negative } \\
\text { mood (NM) }\end{array}$ & & & & & & -.02 & -.02 \\
\hline $\begin{array}{l}\text { Spouse deviation from daily } \\
\text { average NM }\end{array}$ & & & & & & $.02^{\dagger}$ & .01 \\
\hline $\begin{array}{l}\text { Patient gender }(1=\text { female, } \\
\quad 0=\text { male })\end{array}$ & .19 & .03 & .07 & .01 & .09 & .11 & .28 \\
\hline $\begin{array}{l}\text { Patient gender by spouse } \\
\text { average PI }\end{array}$ & & & $.11^{\dagger \mathrm{a}}$ & & & & \\
\hline \# of parameters $/ N$ of days & $18 / 353$ & $20 / 338$ & $22 / 337$ & $22 / 338$ & 22/309 & $22 / 311$ & $28 / 304$ \\
\hline -2 Log likelihood/AIC & $744 / 770$ & $701 / 727$ & $701 / 727$ & $705 / 731$ & $650 / 676$ & $663 / 689$ & $653 / 679$ \\
\hline $\begin{array}{l}\text { Within-person variance/ } \\
\text { between-person variance }\end{array}$ & $.66 / .31$ & $.61 / .27$ & $.58 / .24$ & $.62 / .27$ & $.59 / .27$ & $.63 / .29$ & $.56 / .24$ \\
\hline
\end{tabular}

Note. "Average" physical symptoms, positive interactions, negative interactions and mood indicate Level 2 effects; "Deviation from daily average" indicates Level 1 effects. Controls in all models include years married, husband level of education, and years since arthritis diagnosis.

${ }^{\text {a }}$ Interaction term was included in a separate model that is not shown. See Figure 1 for plot of interaction.

${ }^{\dagger} p \leq .10 .{ }^{*} p \leq .05$. ${ }^{* *} p \leq .01{ }^{* * *} p \leq .001$.

linked with lower arthritis activity and activity limitations. Also, higher than daily average (Level 1) negative mood was linked with higher blood sugar concerns, arthritis activity, and activity limitations (although only at the trend level for the first two outcomes).

To explore how gender of the patient influenced links between predictors and outcomes, gender interactions with predictors also were examined (models not shown). Gender by positive marital interaction effects predicted arthritis activity (at a trend level; $\mathrm{b}=.11, p<.10$ ) as well as activity limitations $(b=.48, p<.01)$.
These patient gender by spouse reports of positive marital interaction effects are illustrated in Figure 1, indicating that arthritis activity and activity limitations were higher for female patients on days where higher levels of positive marital interactions are reported by spouses, and lower where lower positive marital interactions were reported by spouses. For males, marital interactions did not seem related to arthritis activity, although similar to female patients, male patients appeared to report higher health limitations on days where their spouse reported higher positive marital interactions. 
Table 4

Unstandardized Estimates for Spouse Daily Physical Symptoms, Daily Positive and Negative Interactions, Daily Positive and Negative Mood, Predicting Patient Activity Limitations ( $\mathrm{N}=27$ Couples)

\begin{tabular}{|c|c|c|c|c|c|c|c|}
\hline & \multicolumn{7}{|c|}{ Patient activity limitations } \\
\hline & Model 1 & Model 2 & Model 3 & Model 4 & Model 5 & Model 6 & Model 7 \\
\hline & Empty & $\begin{array}{l}\text { Physical } \\
\text { symptoms }\end{array}$ & $\begin{array}{l}\text { Positive } \\
\text { interactions }\end{array}$ & $\begin{array}{l}\text { Negative } \\
\text { interactions }\end{array}$ & $\begin{array}{l}\text { Positive } \\
\text { mood }\end{array}$ & $\begin{array}{l}\text { Negative } \\
\text { mood }\end{array}$ & $\begin{array}{c}\text { All } \\
\text { predictors }\end{array}$ \\
\hline Intercept & 6.77 & 6.45 & 6.54 & 6.46 & 6.27 & 6.53 & 6.42 \\
\hline $\begin{array}{l}\text { Spouse average physical } \\
\text { symptoms (PS) }\end{array}$ & & $.76^{* * * *}$ & $.65^{* * *}$ & $.75^{* * *}$ & $.80^{* * * *}$ & $.66^{* *}$ & .38 \\
\hline $\begin{array}{l}\text { Spouse deviation from daily } \\
\text { average PS }\end{array}$ & & $.37^{* * * *}$ & $.39^{* * *}$ & $.37^{* * * *}$ & $.33^{* * *}$ & $.34^{* * *}$ & $.34^{* * * *}$ \\
\hline $\begin{array}{l}\text { Spouse average positive } \\
\text { interactions (PI) }\end{array}$ & & & .17 & & & & $.31^{*}$ \\
\hline $\begin{array}{l}\text { Spouse deviation from daily } \\
\text { average PI }\end{array}$ & & & -.03 & & & & .07 \\
\hline $\begin{array}{l}\text { Spouse average negative } \\
\text { interactions (NI) }\end{array}$ & & & & -.01 & & & .68 \\
\hline $\begin{array}{l}\text { Spouse deviation from daily } \\
\text { average NI }\end{array}$ & & & & .20 & & & .11 \\
\hline $\begin{array}{l}\text { Spouse average positive } \\
\text { mood }(\mathrm{PM})\end{array}$ & & & & & -.04 & & -.03 \\
\hline $\begin{array}{l}\text { Spouse deviation from daily } \\
\text { average PM }\end{array}$ & & & & & $-.05^{* *}$ & & $-.04^{*}$ \\
\hline $\begin{array}{l}\text { Spouse average negative } \\
\text { mood (NM) }\end{array}$ & & & & & & .05 & .03 \\
\hline $\begin{array}{l}\text { Spouse deviation from daily } \\
\text { average NM }\end{array}$ & & & & & & $.06^{* *}$ & $.05^{*}$ \\
\hline $\begin{array}{l}\text { Patient gender }(1=\text { female, } \\
0=\text { male })\end{array}$ & $1.65^{* *}$ & .69 & $.77^{\dagger}$ & .71 & $.81^{\dagger}$ & .60 & $.99^{\dagger}$ \\
\hline $\begin{array}{l}\text { Patient gender by spouse } \\
\text { average PI }\end{array}$ & & & $.48^{* \mathrm{a}}$ & & & & \\
\hline \# of parameters $/ N$ of days & $19 / 343$ & $21 / 328$ & $23 / 327$ & $23 / 328$ & $23 / 302$ & $23 / 304$ & $29 / 297$ \\
\hline -2 Log likelihood/AIC & $1,396 / 1,422$ & $1,312 / 1,338$ & $1,312 / 1,338$ & $1,312 / 1,338$ & $1,215 / 1,241$ & $1,227 / 1,253$ & $1,212 / 1,238$ \\
\hline $\begin{array}{l}\text { Within-person variance/ } \\
\text { between-person variance }\end{array}$ & $4.89 / 1.74$ & $3.85 / .94$ & $3.78 / .85$ & $3.88 / .97$ & $3.72 / .92$ & $3.96 / 1.11$ & $.56 / .24$ \\
\hline
\end{tabular}

Note. "Average" physical symptoms, positive interactions, negative interactions and mood indicate Level 2 effects; "Deviation from Daily Average" indicates Level 1 effects. Controls in all models include years married, husband level of education, years since diabetes diagnosis, and years since arthritis diagnosis.

${ }^{\text {a }}$ Interaction term was included in a separate model that is not shown. See Figure 1 for plot of interaction.

${ }^{\dagger} p \leq .10 .{ }^{*} p \leq .05$. ${ }^{* * *} p \leq .01$. ${ }^{* * * *} p \leq .001$.

\section{Qualitative Analyses}

As a follow-up to the quantitative analyses, two investigators independently coded one question from the qualitative interviews completed by participants. The question asked how the patient's or spouse's health problems had influenced their marital relationship. The two investigators worked together to make refinements to the themes until consensus was reached.

When women were the patients, positive themes of caregiving $(n=5)$, understanding and empathy $(n=4)$, growth $(n=2)$, and sacrifice $(n=1)$ were identified. The negative theme of the experience being hard on the marriage was identified by four couples. As an example of a positive theme, one husband stated, "I think [health problems have] made it better in a number of ways ... I think we both have been pretty sacrificing for the other ... and we've been supportive of each other ... most things like this will just make us closer."

When men were the patients, fewer couples $(n=2)$ identified positive outcomes such as being closer, understanding each other, and having routines together. A greater number of 


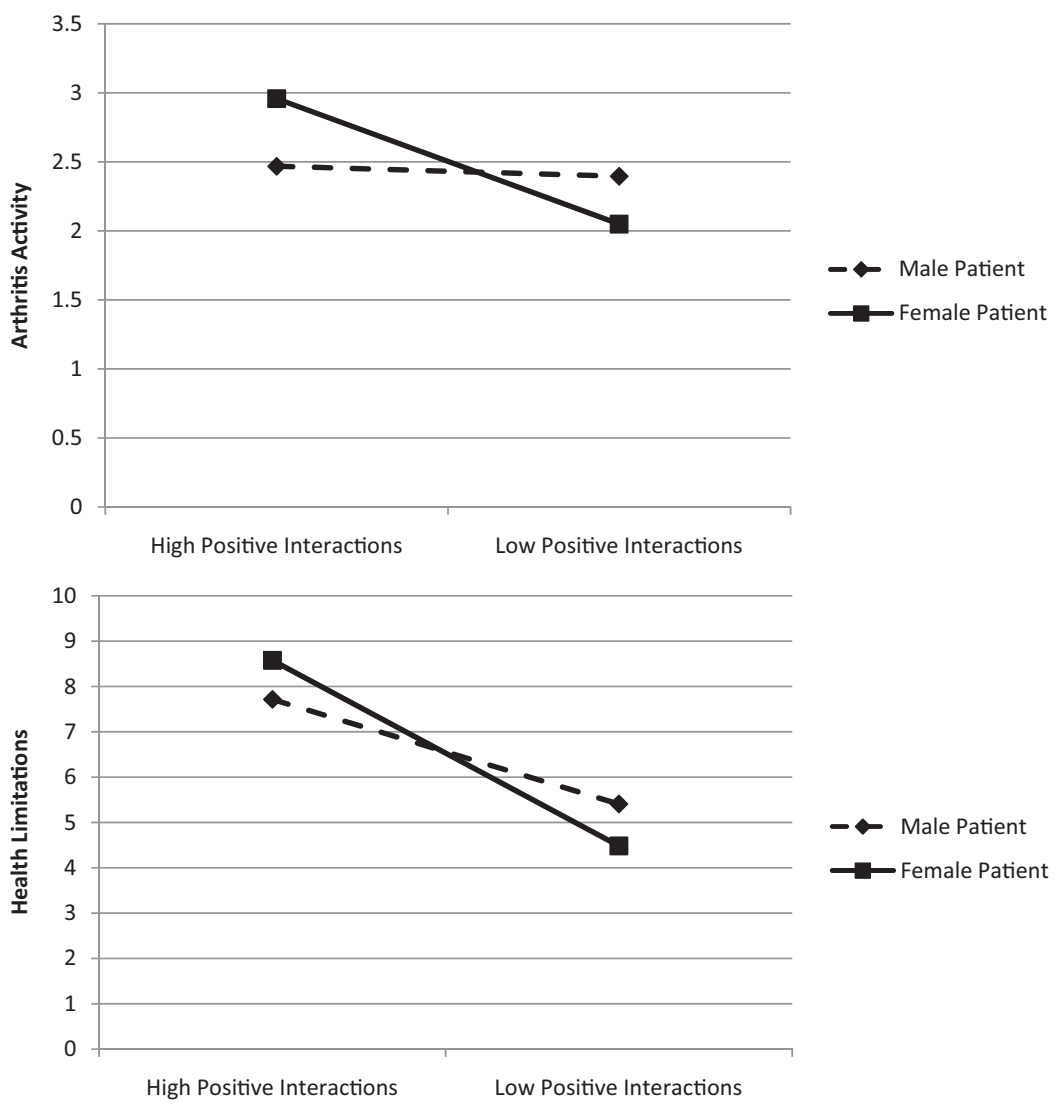

Figure 1. Interaction of gender of patient by spouse's average positive marital interactions predicting arthritis activity and health limitations in the patient.

negative themes were identified, including just managing or making do $(n=5)$, changes in their sexual relationship $(n=5)$, conflict ( $n$ $=1)$, and the experience being hard $(n=1)$. One husband stated, ". . . you don't have the virility that a younger person has, and then of course diabetes affects some people worse that way than it does others, but . . . in the last 10 or 15 years, our love for each other hasn't changed ... but you have different ways of expressing it other than sex." For both male and female patient couples, there were two couples who said that the couple's health problems were unrelated to their marital relationships.

\section{Discussion}

We analyzed daily diary survey reports from 27 patients who had Type 2 diabetes and osteoarthri- tis and their spouses and explored ways that health symptoms, marital interactions, and mood from one spouse may spill over to impact the patient spouse. The study adds to the literature by addressing the effects of perceptions reported by the spouse on the health of a patient with chronic illnesses (see also Pruchno et al., 2009). Furthermore, it shows that even in the presence of spouse health symptoms, their reports of marital interactions and mood predict patient health symptoms, thus providing a snapshot of microprocesses within marital relationships of couples in later life managing multiple chronic illnesses, as well as gendered ways that spillover may occur.

Westman and Vinokur (1998) suggest that experiences of one spouse may influence the other through negative interactions, by empathy or support, or through joint appraisal of health stressors. Regarding our first hypothesis, daily physical symptoms of the spouse were nearly 
always related to daily diabetes concerns, arthritis symptoms, and health limitations of the patient in anticipated directions. These results support the idea that negativity in one can be related to negativity in the other, or that both may experience a bad health day due to joint health stressor appraisals (Berg \& Upchurch, 2007; Berg et al., 2008).

While positive and negative spousal mood were related to patient illness symptoms in expected directions (higher positive and lower negative mood linked to fewer arthritis and diabetes symptoms), positive marital interactions were linked in unanticipated directions with patient symptoms. For example, higher spouse positive marital interactions were linked to higher arthritis activity, possibly indicating some compensation by a spouse for a health symptom flare-up. This trend was especially evident among female patient couples. Qualitative analysis of couple interviews provided some support for idea that marital closeness had increased among couples wherein the wife was the patient spouse, in response to the illnesses. However, qualitative data on a daily basis was not available. Future research using daily qualitative and quantitative data may help to better understand these mechanisms.

Some studies suggest that receiving support from a partner can sometimes have deleterious effects on an ill spouse. For example, in a review of literature related to patients with chronic pain and their caregivers, Newton-John (2002) suggested that supportive responses from spouses may inadvertently become "solicitous" or reinforcing to the patients' pain reports. Also, although support may be linked to greater closeness in couples, it can sometimes simultaneously be linked to greater distress (Gleason, Iida, Shrout, \& Bolger, 2008). For example, Reiss, Gonzales, and Kramer (1986) suggested that greater closeness in families may be linked to poorer health outcomes by not allowing sufficient independence in the ill person. Along these same lines, Turner-Musa, Leidner, Simmens, Reiss, and Kimmel (1999) suggest that ill females may be negatively affected by living in households with more people, as they could feel a sense of obligation to fulfill household duties thereby neglecting to care for their health.

An alternative interpretation of these unanticipated findings is that the patient's health can at times drive marital interactions. It may be that when female patients are experiencing greater arthritis symptoms, spouses may recognize their partner is having a hard day and compensate by increasing positive marital interactions. Indeed, previous research has suggested that the experiences of the patient can and do impact the mental health and marital quality of both (Bigatti \& Cronan, 2002; Pruchno et al., 2009; Yorgason et al., 2006; Yorgason et al., 2008). The increase in positive marital interactions when female patients have more symptoms could be attributed to their seeking partner support more often than male patients (Revenson, Abraído-Lanza, Majerovitz, \& Jordan, 2005), or to "protective buffering," the avoidance of negatives by the spouse in order to lessen patient discomfort (Coyne \& Smith, 1991). This explanation may be particularly salient for older couples, given older adults' greater ability to regulate negative emotions (Scheibe \& Carstensen, 2010).

Lastly, when considering spillover of health from one partner to the other, health behaviors may also provide a mechanism. Specifically, diet and exercise patterns, illness-related knowledge seeking, and treatment adherence may be shared between spouses who have developed lifelong patterns of living. Whether or not shared health behaviors act as pathways for spillover should be addressed in future research.

Therefore, this study adds to the literature by addressing ways that positive daily marital interactions and daily mood predict patient health above and beyond spouse health symptoms. This study highlights the potential value of looking at both positive and negative interactions simultaneously in order to understand more fully the day-to-day experience of living with a chronic illness (Yorgason et al., 2010).

\section{Limitations and Directions for Future Research}

Several limitations should be taken into consideration in interpreting our results, which also provide directions for future research. First, our sample was limited to a small number $(N=27$ couples) of mainly Caucasian couples, with varying lengths of time since diagnosis, who had sought treatment at a diabetes clinic. Consequently, results should be interpreted with caution, recognizing that the associations among partners may not be generalizable to a 
larger, more diverse sample. Furthermore, results from complex multilevel models with small sample sizes should be interpreted with caution, and research with larger samples is needed to confirm our findings. Second, having data only from survey responses potentially limits researchers' ability to identify processes in the couple relationships that are within respondents' conscious thoughts. In addition, survey responses about health symptoms could be reflected in both the symptoms and marital interactions assessed. For example, having pain flare up on a given day could be measured as a symptom or a marital interaction such as not being able to spend leisure time with a spouse. Future research using an observational approach would likely provide a less biased view.

Most couples in the current study reported to be quite happy in their marriages. Couples experiencing lower levels of marital happiness might be different from those in the sample in their daily marital interactions and how they perceive their illnesses. Further research regarding the daily marital interactions, mood, and illness symptoms of unhappy couples could add to our understanding of couple adaptation.

For eight couples in our sample, both spouses had both diabetes and osteoarthritis. Although "spouses" in the sample commonly had multiple chronic conditions themselves, it may be that couple dynamics operate differently when both spouses are managing common health conditions. Future studies might seek to examine potential mediators, such as empathy, as a way to better understand the spillover of emotions (Westman, 2001).

The continued use of daily diary methodologies in future research will be helpful in understanding health mechanisms. Furthermore, because there is a possibility of bidirectionality (patient diabetes concerns, arthritis activity, and activity limitations influencing spouse physical symptoms), additional longitudinal research would allow researchers to better understand challenges associated with later-life illness, and how older individuals manage after living many years with illness. Further qualitative inquiry would allow an in-depth examination of couples' experiences and could potentially help researchers to better understand the meaning of unanticipated findings from the current study. Finally, this study provides a tem- plate for looking at other combinations of comorbid illnesses.

In conclusion, this research addresses a gap in the literature by examining spillover links related to health among later-life couples managing multiple chronic illnesses. Evidence of the spillover of health symptoms in one spouse being linked to diabetes and arthritis symptoms in the patient spouse was found. Furthermore, the spillover of marital interactions and mood, above and beyond physical symptoms, was supported. Further work is needed to better understand the processes involved when positive spousal support is linked with poorer partner health outcomes.

\section{References}

Administration on Aging (AoA). (2009). A profile of older Americans: 2009. U. S. Department of Health and Human Services: Washington, DC. Retrieved from http://www.aoa.gov/AoARoot/Aging_Statistics/Profile/ 2009/docs/2009profile_508.pdf

Bayliss, E. A., Steiner, J. F., Fernald, D. H., Crane, L. A., \& Main, D. S. (2003). Descriptions of barriers to self-care by persons with domorbid chronic diseases. Annals of Family Medicine, 1, 15-21. doi:10.1370/afm.4

Berg, C. A., \& Upchurch, R. (2007). A developmental-contextual model of couples coping with chronic illness across the adult life span. Psychological Bulletin, 133, 920-954. doi:10.1037/00332909.133.6.920

Berg, C. A., Wiebe, D., Butner, J., Bloor, L., Bradstreet, C., Upchurch, R., . . Patton, G. (2008). Collaborative coping and daily mood in couples dealing with prostate cancer. Psychology and Aging, 23, 505-516. doi:10.1037/a0012687

Bigatti, S. M., \& Cronan, T. A. (2002). An examination of the physical health, health care use, and psychological well-being of spouses of people with fibromyalgia syndrome. Health Psychology, 21, 157-166. doi:10.1037/0278-6133.21.2.157

Bolger, N., Davis, A., \& Rafaeli, E. (2003). Diary methods: Capturing life as it is lived. Annual Review of Psychology, 54, 579-616. doi:10.1146/ annurev.psych.54.101601.145030

Bookwala, J., \& Schulz, R. (1996). Spousal similarity in subjective well-being: The cardiovascular health study. Psychology and Aging, 11, 582-590. doi: 10.1037/0882-7974.11.4.582

Booth, A., \& Johnson, D. R. (1994). Declining health and marital quality. Journal of Marriage and the Family, 56, 218-223. doi:10.2307/352716

Burgener, S., \& Twigg, P. (2002). Relationships among caregiver factors and quality of life in care 
recipients with irreversible dementia. Alzheimer Disease and Associated Disorders, 16, 88-102. doi:10.1097/00002093-200204000-00006

Center on an Aging Society. (2003). Multiple chronic conditions: A challenge for the 21st century. Challenges for the 21st century: Chronic and disabling conditions. Washington, DC: Georgetown University. Retrieved from http://ihcrp.georgetown.edu/ agingsociety/pdfs/multiple.pdf

Coyne, J. C., \& Smith, D. A. F. (1991). Couples coping with a myocardial infarction: A contextual perspective on wives' distress. Journal of Personality and Social Psychology, 61, 404-412. doi: 10.1037/0022-3514.61.3.404

Gleason, M. E. J., Iida, M., Shrout, P., \& Bolger, N. (2008). Receiving support as a mixed blessing: Evidence for dual effects of support on psychological outcomes. Journal of Personality and Social Psychology, 94, 824-838. doi:10.1037/0022-3514 .94.5.824

Gunthert, K. C., \& Wenze, S. J. (2012). Daily Diary Methods. In M. R. Mehl \& T. S. Conner (Eds.), Handbook of research methods for studying daily life (pp. 144-159). New York, NY: Guilford Press.

Hays, R. D., Sherbourne, C. D., \& Mazel, R. M. (1993). The RAND 36-item health survey 1.0. Health Economics, 2, 217-227. doi:10.1002/hec .4730020305

Henry, N. J. M., Berg, C. A., Smith, T. W., \& Florsheim, P. (2007). Positive and negative relationship characteristics and their association with marital satisfaction in middle-aged and older couples. Psychology and Aging, 22, 428-441. doi: 10.1037/0882-7974.22.3.428

Iida, M., Stephens, M. A. P., Rook, K. S., Franks, M. M., \& Salem, J. K. (2010). When the going gets tough, does support get going? Determinants of spousal support provision to type 2 diabetic patients. Personality and Social Psychology Bulletin, 36, 780-791. doi:10.1177/0146167210369897

Larsen, R. J., \& Kasimatis, M. (1991). Day-to-day physical symptoms: Individual differences in the occurrence, duration, and emotional concomitants of minor daily illnesses. Journal of Personality, 59, 387-423.

Larson, R. W., \& Almeida, D. M. (1999). Emotional transmission in the daily lives of families: A new paradigm for studying family process. Journal of Marriage and the Family, 61, 5-20. doi:10.2307/ 353879

Laurenceau, J. P., \& Bolger, N. (2005). Using diary methods to study marital and family processes. Journal of Family Psychology, 19, 86-97. doi: 10.1037/0893-3200.19.1.86

Lawrence, R. C., Helmick, C. G., Arnett, F. C., Deyo, R. A., Felson, D. T., Giannini, E. H., . . . Wolfe, F. (1998). Estimates of arthritis and selected musculoskeletal disorders in the United States. Arthritis
\& Rheumatism, 41, 778-799. doi:10.1002/15290131(199805)41:5<778::AID-ART4>3.0.CO; 2-V

Neff, L. A., \& Karney, B. R. (2005). Gender differences in social support: A question of skill responsiveness? Journal of Personality and Social Psychology, 88, 79-90. doi:10.1037/0022-3514.88 .1 .79

Newton-John, T. R. O. (2002). Solicitousness and chronic pain: A critical review. Pain Reviews, 9, 7-27. doi:10.1191/0968130202pr186ra

Pastor, P. N., Makuc, D. M., Reuben, C., \& Xia, H. (2002). Chartbook on trends in the health of Americans: Health, United States, 2002. Hyattsville, MD: National Center for Health Statistics. Retrieved from http://www.cdc.gov/nchs/data/hus/ hus02.pdf

Piazza, J. R., Charles, S. T., \& Almeida, D. M. (2007). Living with chronic health conditions: Age differences in affective well-being. The Journals of Gerontology. Series B: Psychological Sciences and Social Sciences, 62, P313-P321.

Pruchno, R. D., Wilson-Genderson, M., \& Cartwright, F. (2009). Self-rated health and depressive symptoms in patients with end-stage renal disease and their spouses: A longitudinal study dyadic analysis of late-life marriages. The Journals of Gerontology. Series B: Psychological Sciences and Social Sciences, 64B, 212-221. doi:10.1093/ geronb/gbp006

Reiss, D., Gonzalez, S., \& Kramer, N. (1986). Family process, chronic illness, and death: On the weakness of strong bonds. Archives of General Psychiatry, 43, 795-804. doi:10.1001/archpsyc.1986 .01800080081011

Revenson, T. A., Abraído-Lanza, A. F., Majerovitz, S. D., \& Jordan, C. (2005). Couples coping with chronic illness: What's gender got to do with it? In T. A. Revenson, K. Kayser, \& G. Bodenmann (Eds.) Couples coping with stress: Emerging perspectives on dyadic coping (pp. 137-156). Washington, DC: American Psychological Association.

Scheibe, S., \& Carstensen, L. L. (2010). Emotional aging: Recent findings and future trends. The Journals of Gerontology. Series B: Psychological Sciences and Social Sciences, 65B, 135-144. doi: 10.1093/geronb/gbp132

Shavelson, R. J., \& Webb, N. M. (1991). Generalizability theory: A primer. Newbury Park, CA: Sage.

Stephens, M. P., Martire, L. M., Creamans-Smith, J. K., Druley, J. A., \& Wojno, W. C. (2006). Older women with osteoarthritis and their caregiving husbands: Effects of pain and pain expression on husbands' well-being and support. Rehabilitation Psychology, 51, 3-12. doi:10.1037/0090-5550.51 .1 .3

Story, T. N., Berg, C. A., Smith, T. W., Beveridge, R., Henry, N. J. M., \& Pearce, G. (2007). Age, 
marital satisfaction, and optimism as predictors of positive sentiment override in middle-aged and older married couples. Psychology and Aging, 22, 719-727. doi:10.1037/0882-7974.22.4.719

Turner-Musa, J., Leidner, D., Simmens, S., Reiss, D., \& Kimmel, P. L. (1999). Family structure and patient survival in an African-American end-stage renal disease population: A preliminary investigation. Social Science \& Medicine, 48, 1333-1340. doi:10.1016/S0277-9536(98)00437-7

Watson, D., Clark, L. A., \& Tellegen, A. (1988). Development and validation of brief measures of positive and negative affect: The PANAS scales. Journal of Personality and Social Psychology, 54, 1063-1070. doi:10.1037/0022-3514.54.6.1063

Westman, M. (2001). Stress and strain crossover. Human Relations, 54, 717-751. doi:10.1177/ 0018726701546002

Westman, M., Keinan, G., Roziner, I., \& Benyamini, Y. (2008). The crossover of perceived health between spouses. Journal of Occupational Health Psychology, 13, 168-180. doi:10.1037/1076-8998 .13.2.168

Westman, M., \& Vinokur, A. (1998). Unraveling the relationship of distress levels within couples: Common stressors, empathic reactions, or crossover via social interaction? Human Relations, 51, 137-156. doi:10.1177/001872679805100202

Whittemore, R., Urban, A. D., Tamborlane, W. V., \& Grey, M. (2003). Quality of life in school-aged children with type 1 diabetes on intensive treat- ment and their parents. The Diabetes Educator, 29, 847-854.

Wray, L. A., Alwin, D. F., McCammon, R. J., Manning, T., \& Best, L. E. (2006). Social status, risky health behaviors, and diabetes in middle- aged older adults. The Journals of Gerontology. Series B: Psychological Sciences and Social Sciences, 61B, S290-S298.

Xu, J. Q., Kochanek, K. D., Murphy, S. L., TejadaVera, B. (2010). Deaths: Final data for 2007 (National Vital Statistics Reports, vol. 58, no. 19). Hyattsville, MD: National Center for Health Statistics.

Yorgason, J. B., Almeida, D., Neupert, S. D., Spiro, A., \& Hoffman, L. (2006). A dyadic examination of daily health symptoms and emotional wellbeing in later-life couples. Family Relations: Interdisciplinary Journal of Applied Family Studies, 55, 613-624. doi:10.1111/j.1741-3729.2006 $.00430 . x$

Yorgason, J. B., Booth, A., \& Johnson, D. (2008). Health, disability, and marital quality: Is the association different for younger versus older cohorts? Research on Aging, 30, 623-648. doi:10.1177/ 0164027508322570

Yorgason, J. B., Roper, S. O., Wheeler, B., Crane, K., Byron, R., Carpenter, L., . . . Higley, D. (2010). Older couples' management of multiple-chronic illnesses: Individual and shared perceptions in coping with type 2 diabetes and osteoarthritis. Families, Systems, \& Health, 28, 30-47. doi:10.1037/ a0019396 


\section{Appendix}

\section{Multilevel Model Equations Used in The Analysis of The Study}

An example of the final main effects multilevel model equation illustrates this analysis for each of the three outcomes.

\section{Level 1 Model}

$$
\begin{aligned}
\text { Health }_{\mathrm{ti}}= & \beta_{0 i}+\beta_{1 i}\left(\text { DevSymp }_{\mathrm{ti}}\right) \\
& +\beta_{2 i}\left(\text { DevPI }_{\mathrm{ti}}\right)+\beta_{3 i}\left(\text { DevNI }_{\mathrm{ti}}\right) \\
& +\beta_{4 i}\left(\text { DevPmood }_{\mathrm{ti}}\right) \\
& +\beta_{5 i}\left(\text { DevNMood }_{\mathrm{ti}}\right)+e_{t i}
\end{aligned}
$$

where the predicted value for the patient health outcome (e.g., daily diabetes concerns), for each patient " $i$ " on a given day " $t$," is a function of their average health (intercept; $\beta_{O i}$ ), plus the spouses' daily deviation from their average physical symptoms $\left(\beta_{l i}\right)$, positive marital interactions $\left(\beta_{2 i}\right)$, negative marital interactions $\left(\beta_{3 i}\right)$, positive mood $\left(\beta_{4 i}\right)$, negative $\operatorname{mood}\left(\beta_{5 i}\right)$, plus residual variation in the outcome on a given day $\left(e_{t i}\right)$.

\section{Level 2 Model}

$$
\begin{aligned}
\beta_{0 \mathrm{i}} & =V_{00}+V_{01}\left(\text { AveSymp }_{i}\right)+V_{02}\left(\text { AvePI }_{i}\right) \\
& +V_{03}\left(\text { AveNI }_{i}\right)+V_{04}\left(\text { AvePMood }_{i}\right) \\
& +V_{05}\left(\text { AveNMood }_{i}\right) \\
& +V_{06}\left(\text { PatientGender }_{i}\right)+\mathrm{U}_{0 i}
\end{aligned}
$$

where the average patient health outcome (intercept) is a function of the sample average of patient health $\left(\mathrm{V}_{00}\right)$, plus a given spouses' average symptom level $\left(\mathrm{V}_{01}\right)$, their average positive marital interaction $\left(\mathrm{V}_{02}\right)$, average negative marital interaction $\left(\mathrm{V}_{03}\right)$, average positive mood $\left(\mathrm{V}_{04}\right)$, average negative mood $\left(\mathrm{V}_{05}\right)$, and patient gender $\left(\mathrm{V}_{06}\right)$, plus random deviation from the sample average (random intercept; $\mathrm{U}_{0 \mathrm{i}}$ ).

Received January 16, 2012 Revision received September 4, 2012 Accepted September 21, 2012 